\title{
Diagnosing Housing Bubbles across Rich Countries
}

\author{
Akhter Faroque $^{1} \&$ Stanley A. Koren ${ }^{2}$ \\ ${ }^{1}$ Department of Economics, Laurentian University, Sudbury, Canada \\ ${ }^{2}$ Department of Psychology, Laurentian University, Sudbury, Canada \\ Correspondence: Akhter Faroque, Department of Economics, Laurentian University, Sudbury Ontario, P3E 2C6, \\ Canada. E-mail: afaroque@laurentian.ca
}

Received: February 6, 2018

Accepted: March 17, 2018

Online Published: March 20, 2018

doi:10.5539/ijef.v10n4p179

URL: https://doi.org/10.5539/ijef.v10n4p179

\begin{abstract}
This paper addresses an empirical puzzle in the housing bubble literature: models of market fundamentals perform poorly in explaining investor exuberance in housing even though, individually, many fundamentals have strong ability to predict explosive growth in real house prices. We explore two plausible sources for the poor performance: missing fundamentals and missing bubble dynamics. To shed light on the relative importance of these sources, we conduct a detailed two-step investigation of the housing markets in ten rich countries using models, methodologies and datasets that are similar to those employed in the existing literature. Our findings consistently show that the predictive ability of models of market fundamentals can be dramatically enhanced once missing dynamics of housing bubbles are properly accounted for. GSADF denotes Generalised Sup Augmented Dickey-Fuller test and SADF denotes Sup Augmented Dickey-Fuller test.
\end{abstract}

Keywords: housing bubble dynamics, GSADF test, dynamic probit models

\section{Introduction}

A substantive body of recent research has explored the possibility of predicting housing bubbles before they burst. No doubt this surge in research interest has been fueled, in part, by the massive social and economic dislocations of the 'great recession' which quickly followed on the heels of the global housing boom-bust cycle of the past decade. But besides greater awareness of costs, two other factors may also have contributed to this surge in research interest. The first is that house prices have continued to grow relative to the fundamentals in many rich countries, with only a brief break during the recession of 2008-2009 (IMF, 2016). Growing concern about housing affordability for an increasingly larger segment of the population has drawn the attention of researchers and prompted calls for policy actions for reigning in house prices. The second factor concerns recent development of powerful statistical tools for testing and date-stamping asset price bubbles (Phillips \& Yu, 2011, Phillips et al., 2013). These methodological improvements have made it possible for researchers to formally test the existence of and also estimate the likely origination and termination dates of asset-price bubbles much more accurately than was possible with traditional methodologies. Furthermore, the new tools hold out the promise for policymakers of the ability to monitor bubble-like developments in real time and adopt policies that can 'cool' an overheated housing market before things get out of hand.

Preliminary evidence from this body of research seems quite encouraging, as it suggests that, given the underlying fundamental drivers of exuberance, relevant data, and the new methodological tools, it may indeed be possible to detect and also date-stamp an incipient housing bubble in real time. But, the evidence also contains a puzzle in that it shows that even though several market fundamentals (demand and supply factors) are significantly correlated with explosive growth in house prices, fundamentals as a group exhibit only a limited ability to explain explosive growth in house prices in many rich countries (Pavlidis et al., 2016). While this implies that bubble-like (explosive) growth in house prices may contain an element of speculative exuberance, the literature fails to address the issue of whether the poor model performance is the result of misspecification due to missing fundamentals or missing dynamics of the bubble process.

The primary purpose of this paper is to examine whether missing fundamentals or missing dynamics is responsible for the poor performance of empirical housing bubble models typically used in the literature. More specifically, we argue that, among the various observable characteristics of housing bubbles, two are critical for modelling and predicting bubbles. The first is that, during a bubble period, real house prices experience 
exponential growth due to excessive investor exuberance in housing (Phillips et al., 2013). The second is that the bubble process is inherently dynamic; it has strong momentum, meaning that explosive growth in house prices in the current period is likely to be followed by similar growth in the next period. Such momentum of the bubble process is, in fact, predicted by alternative bubble theories in which speculative exuberance of investors in the current period is sustained over time by exaggerated expectations (rational or extrapolative) of higher prices in the future (Blanchard, 1979; Shiller, 2000).

In this paper we conduct a detailed cross-country empirical investigation of the housing markets in ten rich countries by employing models, methodologies and datasets similar to those used in extant literature, with the aim to demonstrate that a proper accounting of the dynamics of the bubble process is critical for our ability to identify, explain, and date-stamp bubble formation in the housing market. Our investigation covers housing markets in Australia, Canada, Italy, Japan, Norway, Sweden, Switzerland, United Kingdom and the United States over the common sample period 1975Q1 - 2016Q1. It is implemented in two separate steps. In step 1, we test for the existence of bubble-like explosive growth in real house prices in each country and also estimate the likely beginning and the termination dates of each episode of explosive growth. For this purpose, we rely on the most powerful available test called the Generalized Supremum Augmented Dickey-Fuller (GSADF) test (Phillips et al., 2013). The evidence from the GSADF test reveals that all ten countries have experienced at least one major episode of explosive growth during the sample period; a few countries have experienced three or four. It should be noted, however, that despite its ability to accurately detect and date stamp episodes of explosive growth, the results of the univariate GSADF test by themselves, do not tell us anything about the underlying causes for such growth. In particular, the GSADF test cannot distinguish whether the underlying drivers of explosive growth are changes in the fundamentals or speculative exuberance of homebuyers.

Therefore, in step 2 of our investigation, we employ multivariate probit models with a view to quantify the relative abilities of fundamentals vs speculative exuberance in explaining the likelihood of bubble formation in each country. To facilitate this differentiation, we invoke modern bubble theories that imply that when explosive growth is caused by speculative exuberance of investors, it should leave a clear footprint of a strong pattern of autocorrelation (momentum) in house prices while, by contrast, when such growth is driven by changes in fundamentals, they should leave a systematic pattern of cross correlations (see section 2 for more details).

We start our empirical investigation by estimating a general probit model for each country that includes a large number of fundamental explanatory variables. Then, to derive country-specific probit models we recursively eliminate all statistically insignificant variables (i.e., with the highest $\mathrm{p}$ values) until all remaining variable are statistically significant. This so called general-to-specific modelling strategy reduces the risk that missing fundamentals are the cause for the poor model fit. Next, we examine the predictive abilities of two separate variants of the country-specific models. The first is a static model designed to helps us assess the quantitative predictive power of the country-specific fundamentals at different forecast horizons. The use of lagged fundamentals in the construction of the static model also reduces the risk that missing fundamentals are at the root of the model's predictive failure. Finally, we consider a dynamic probit model derived by augmenting the static model with a lagged dependent variable intended to capture the momentum in the bubble process. The additional predictive ability of the lagged dependent variable measures the quantitative strength of investor exuberance in housing during a bubble process in each country.

Our paper makes two notable contributions. First, while the extant evidence shows that that the housing bubble of the past decade originated in the US housing market and then quickly spread to many other rich countries (Pavlidis et al., 2016), our findings in this paper also show that fundamental drivers of bubble-like explosive growth in house prices differ markedly across countries. Second, while confirming the extant finding that static models perform poorly across all countries, our paper offers new evidence that show that dynamic models that explicitly account for the momentum of the bubble process, fit the data better and have markedly higher predictive ability across all countries and all forecast horizons.

Section 2 conducts a selective survey of the literature to highlights our central thesis and the dynamics of housing bubbles that have motivated the detailed cross-country empirical investigation undertaken in this paper. Section 3 briefly describes the GSADF test and applies it to real house prices in ten rich countries and interprets the results. Section 4 estimates the country-specific static and dynamic probit models and reports the estimation results from the models. Section 5 concludes the paper.

\section{Background Literature: Overvaluation, Explosive Growth and the Fundamentals}

The literature on housing bubbles is vast. For the purposes of this paper, we classify this literature into two broad approaches: the traditional approach and the modern approach. We conduct a short and selective survey of these 
alternative approaches with a view to highlight the central bubble hypothesis and the dynamics of the housing bubbles process that have motivated our empirical investigation of the housing markets in ten rich countries in this paper. Our central thesis in this paper is that even episodes of very rapid (exponential) growth in real house prices may not be bubbles because, as our literature review shows, rapid run-ups in house prices may be caused either by excessive investor exuberance (rational or irrational) in housing or by shifts in the housing market fundamentals that are unrelated to speculative exuberance of investors.

Housing bubble studies conducted under the traditional approach typically define bubbles as overvaluation of house price and equate the size of the overvaluation to the gap between the actual and the fundamental price of housing. An important advantage of this approach is that it allows researchers a great deal of flexibility to employ a variety of models and methodologies for estimating the unobserved fundamental price. But an associated disadvantage is that, in the absence of a generally accepted model of the fundamentals (Mayer, 2011; Igan \& Louhgani, 2012), the flexibility this approach affords researchers also means that the estimate of the fundamental price and, therefore, the inference drawn about the existence of bubbles, may vary widely from one researcher to another. For example, based on the scholarly research conducted in the years leading up to the U.S. housing bust in 2006, economists reached diametrically opposite conclusions about whether or not the U.S. was experiencing a housing bubble (Himmelberg et al., 2005; Shiller, 2005).

The modern approach to housing bubbles circumvents the limitation of the traditional approach noted above, by defining bubbles, not simply as overvaluation, but rather as rare episodes of very rapid (exponential) growth in real house prices. Unlike overvaluation, exponential growth is directly observable; this makes the statistical detection of a bubble and the period over which it lasts somewhat easier (see section 3 below). Even more importantly, exponential growth and its dynamics as defining characteristics of bubbles are easy to justify, as they arise quite naturally in alternative modern theories of speculative bubbles.

Economic historians (Kindleberger, 1986; Shiller, 2003) have recorded that speculative asset price bubbles are a dynamic phenomenon that develop through time in several phases. The initial phase is a benign housing boom triggered by some favourable shift in one of the fundamentals (low interest rates, loosening of credit conditions, capital inflows). During this phase, house prices grow steadily, unnoticed by the general public and may be easily justified by the fundamentals. Phase two attracts two types of investors to the housing markets: first-time homebuyers motivated by fear of being priced out of the market if they wait, and speculators who enter the market purely in the expectations of making capital gains from trading houses. The entry of these new buyers speed up the growth of house prices over time; but this only feeds into greater investor confidence that prices will continue to grow in the future and draws in more speculators. The result may be persistent exponential growth in real house prices, which become further and further detached from the fundamental price.

Modern bubble theories attribute exponential growth to alternative expectation mechanisms. In theories of rational bubbles (Blanchard, 1979; Summers, 1986), knowledgeable, forward-looking investors are willing to buy overpriced houses today, only because they expect to be able to sell them to others at even higher prices in the future. In contrast, in non-rational theories of bubbles, novice homebuyers may mechanically extrapolate from observed rapid growth in house prices in the recent past into expectations of rapid growth in house prices in the present. In both types of theories, explosive growth in prices are sustained over time through a positive feedback mechanisms, by which current prices grow rapidly only because speculators expect prices to continue to grow in the future. Such autoregressive processes are inherently unstable and are only sustained as long investor expectations are fulfilled; this implies that a bubble may burst anytime when investors' expectations of outsized capital gains go unrealized and prompts them to reverse their expectations (Shiller, 2003).

A complicating factor is that, unlike stocks, housing markets are highly segmented regionally and in terms of quality; thus, price can vary widely across regions and over time, reflecting relative supply and preference structures. In locations where the supply of land for housing development is highly inelastic in the short run due to geography or zoning laws, shift in housing demand due to a change in one of the fundamentals may cause substantial short-term overvaluation of price relative to the trend (fundamental) price (Peterson \& Zheng, 2011-2012). Furthermore, houses are an asset that not only promises to pay a monetary return but also serves as a symbol of social status - signaling their owners' high relative standing within society (Turner, 2013). As income grows, demand and price of housing may grow more than proportionately to income, as home buyers compete for the right to live in the "nice" parts of a city where exclusivity is accomplished through higher prices. Finally, house price surges can also be shaped by the mortgage financing system of a country (Tsatsaronis \& Zhou, 2004). Several features of the mortgage finance system may promote property price cycles, including whether the system offers the possibility of mortgage equity withdrawal or securitization of mortgage assets. 
The upshot is that considerable care must be taken to assess whether soaring house prices are the result of excessive speculation or changes in the housing market fundamentals. Modern theories of speculative bubbles suggest that, any evidence of bubble-like explosive growth in house prices must be supplemented with further evidence about the role of the fundamentals and also the role of dynamics of the bubble process, for a proper diagnosis of whether or not a speculative bubble exists. In section 3 below, we first assemble cross-country evidence of bubble-like explosive growth in house prices and then, in section 4 below, evaluate the roles play by economic fundamentals and by the dynamics of the bubble process.

\section{Evidence of Explosive Growth in House Prices in Rich Countries}

This section first describes the GSADF test for detecting and date-stamping episodes of bubble-like explosive growth in a time series that may contain multiple such episodes (see section 3.1). We then apply the test to the real house price series of ten OECD countries over the period 1975Q1-2016Q1 and report the results (see section 3.2).

\subsection{The GSADF Test of Explosive Growth in Real House Prices}

The basic building block for the GSADF test (Phillips et al., 2013) and also of the competing Sup ADF (SADF) test (Phillips et al., 2011) is the right-tailed Augmented Dickey Fuller (ADF) unit root test, based on the assumption that the real house price series $\mathrm{y}_{\mathrm{t}}$ follows the following first-order autoregressive model

$$
y_{t}=\mu+\delta y_{t-1}+\sum_{i=1}^{k} \varphi_{i} \Delta y_{t-i}+\varepsilon_{t}
$$

The null hypothesis for both tests is that, when driven only by the fundamentals, growth in $\mathrm{y}_{\mathrm{t}}$ evolves at most as a unit root process. The alternative hypothesis is that, when non-fundamentals, such as excessive speculation, also exert a strong influence, growth in $\mathrm{y}_{\mathrm{t}}$ follows an exponential (bubble) process. It should be noted that both the unit root and the exponential processes have stochastic trends, but the former grows slowly while the later grows explosively. More formally, the null and the alternative hypotheses for each test are:

$\mathrm{H}_{0}: \delta \leq 1$ ( $\mathrm{y}_{\mathrm{t}}$ does not contain explosive growth).

$\mathrm{H}_{1}: \delta>1$ ( $\mathrm{y}_{\mathrm{t}}$ contains one or more episodes of explosive growth).

The right-tailed ADF statistic is the usual t-statistic (the estimate of $\delta$ divided by its standard error) in equation 1 . However, the critical values for testing the null hypothesis are now taken from the right tail of the ADF statistic's non-normal distribution.

What distinguishes the GSADF test from the SADF test is that the GSADF test employs a more powerful and efficient search procedure for detecting and date stamping explosive growth. In particular, when the series $\mathrm{y}_{\mathrm{t}}$ contains episodes of multiple collapsing bubbles in the sample, the search procedures employed in the SADF test may fail to detect them, because past collapsing bubbles may make the data look rather stationary (Evans, 1991). The GSADF test overcomes this difficulty by measuring explosive growth at each observation over all backward-looking intervals of variable sizes. For example, to test whether or not there is bubble at the $100^{\text {th }}$ observation, this procedure calculates ADF t statistics for each of the intervals that end at the $100^{\text {th }}$ observation such as $\{1,2,3 \ldots 100\},\{2,3 \ldots 100\}$ up to $\{70,71 \ldots 100\}$ (a minimum number of observations are needed to run equation (1) and calculate t-statistic). It then compares the maximum over all $70 \mathrm{t}$-statistics to a quantile from their distribution. The origination date of an episode of explosive growth is the first observation whose backward sup ADF (BSADF) statistic exceeds the critical value and the termination date is the first observation after the start date whose BSADF statistic falls below the critical value. The finite sample critical values for the test statistics are based on Monte-Carlo simulations using the following random walk process with an asymptotically vanishing drift as the null

$$
y_{t}=d / T^{\eta}+\theta y_{t-1}+\varepsilon_{t}
$$

where $\mathrm{T}$ is the sample size and $\varepsilon_{\mathrm{t}}$ is the error term, and the $\mathrm{d}, \eta$ and $\theta$ are constants set at unity (Phillips et al., 2013).

It is notable that the procedure described here potentially provides a real-time empirical tool for determining whether or not a potential bubble exists at any given point in time; only current and past information is needed and there is no look-ahead bias involved.

\subsection{Chronology of Housing Exuberance in Rich Countries}

For Table 1 reports the results of the univariate GSADF test applied to real house prices from ten rich countries over the period 1975Q1-2016Q1. The test is implemented by setting the initial window size at $15 \%$ of the sample (25 quarterly observations). The parameters that define the unit root null hypothesis for the test are set at values 
suggested by Phillips et al. (2013) and the finite-sample critical values for the tests are obtained from bootstrap Monte-Carlo simulations with 2000 replications.

Table 1. Episodes of explosive growth in real house prices based on the GSADF test: 1975Q1-2016Q1

\begin{tabular}{|c|c|c|c|c|c|c|}
\hline $\begin{array}{l}\text { Country } \\
\text { Australia }\end{array}$ & $\begin{array}{c}\text { GSADF Test Statistic } \\
10.27^{* * *}\end{array}$ & \multicolumn{2}{|c|}{ Critical values } & \multicolumn{3}{|c|}{ Origination \& termination dates of each episode of explosive growth } \\
\hline Australia & $10.27 * * *$ & $\begin{array}{l}90 \% \\
95 \% \\
99 \%\end{array}$ & $\begin{array}{l}1.48 \\
2.05 \\
2.68\end{array}$ & 1988Q2-1989Q2 & 1998:Q2-1008Q2 & 2009Q1-2010Q4 \\
\hline Canada & $10.12 * * *$ & $\begin{array}{l}90 \% \\
95 \% \\
99 \%\end{array}$ & $\begin{array}{l}1.48 \\
1.25 \\
1.89\end{array}$ & $\begin{array}{l}\text { 1980Q4-1981Q4 } \\
\text { 2004Q3-2016Q1 }\end{array}$ & 1988Q4-1989Q3 & 2002Q1-2008Q3 \\
\hline Ireland & $6.79 * * *$ & $\begin{array}{l}90 \% \\
95 \% \\
99 \%\end{array}$ & $\begin{array}{l}1.48 \\
2.14 \\
2.87\end{array}$ & 1985Q2-1987Q4 & 1996Q1-2000Q2 & 2002Q3-2007Q4 \\
\hline Italy & $2.84 * *$ & $\begin{array}{l}90 \% \\
95 \% \\
99 \%\end{array}$ & $\begin{array}{l}1.48 \\
2.14 \\
2.87\end{array}$ & 1989Q2-1989Q4 & 2003Q1-2005Q2 & \\
\hline Japan & $5.01 * * *$ & $\begin{array}{l}90 \% \\
95 \% \\
99 \%\end{array}$ & $\begin{array}{l}1.48 \\
2.14 \\
2.87\end{array}$ & $\begin{array}{l}\text { 1987Q1-1988Q2 } \\
\text { 2012Q1-2015Q3 }\end{array}$ & 1988Q3-1991Q4 & 2002Q2-2006Q4 \\
\hline Spain & $2.41 * *$ & $\begin{array}{l}90 \% \\
95 \% \\
99 \%\end{array}$ & $\begin{array}{l}1.48 \\
2.14 \\
2.87\end{array}$ & 1982Q3-1984Q2 & 2001Q1-2007Q4 & \\
\hline Sweden & $5.21 * * *$ & $\begin{array}{l}90 \% \\
95 \% \\
99 \%\end{array}$ & $\begin{array}{l}1.48 \\
2.14 \\
2.87\end{array}$ & $\begin{array}{l}\text { 1982Q4-1983Q2 } \\
\text { 2014Q3-2016Q1 }\end{array}$ & 1999Q1-2001Q4 & 2002Q1-2008Q3 \\
\hline SWITZ & $4.09 * * *$ & $\begin{array}{l}90 \% \\
95 \% \\
99 \%\end{array}$ & $\begin{array}{l}1.48 \\
2.14 \\
2.87\end{array}$ & 1996Q3-1998Q1 & 2009Q2-2016Q1 & \\
\hline UK & $3.38 * * *$ & $\begin{array}{l}90 \% \\
95 \% \\
99 \%\end{array}$ & $\begin{array}{l}1.48 \\
2.14 \\
2.87\end{array}$ & $\begin{array}{l}\text { 1987Q2-1989Q2 } \\
\text { 2006Q4-2008Q1 }\end{array}$ & 1999Q2-2000Q1 & 2000Q2-2005Q1 \\
\hline USA & $3.82 * * *$ & $\begin{array}{l}90 \% \\
95 \% \\
99 \%\end{array}$ & $\begin{array}{l}1.48 \\
2.14 \\
2.87\end{array}$ & 1997Q1-2007Q2 & & \\
\hline
\end{tabular}

Note. $*, * *$ and $* * *$ denote statistical significance at the 10,5, and 1 percent levels respectively. All results in this table are for autoregressive lag length $\mathrm{k}=4$. Data Source: The authors acknowledge use of the dataset described in Mack and Martínez-García (2011). Data are publicly available from the International House Price Database, Federal Reserve Bank of Dallas.

For each country, Table 1 reports the GSADF statistic for the null hypothesis of no explosive growth in real house prices, the $99 \%, 95 \%$ and $90 \%$ critical values, and the estimated origination and termination dates for each statistically significant episode of explosive dynamics. The origination date of an episode of explosive growth corresponds to the first observation that the BSADF statistic exceeds the $100(1-\alpha) \%$ critical value obtained from the bootstrap procedure, and the termination date corresponds to the first observation that the BSADF statistic falls below the $100(1-\alpha) \%$ critical value.

Three notable findings emerge from the results reported in Table 1. First, all ten countries have experienced at least one significant episode of housing market exuberance (bubble-like exponential growth in real house prices) during the sample period. For purposes of illustration, consider the case of Australia (see row 1 of Table 1). The estimated GSADF statistic (10.27) by far exceeds the 99\% critical value (2.68), strongly indicating that the country has experienced at least one major episode of housing market exuberance. The exact number of such episodes is three - the origination and termination dates for each episode are 1988Q2-1989Q2, 1998:Q2-1008Q2 and 2009Q1-2010Q4, as shown in the last column (row 1) of table 1. For convenient visual illustration, we have also shown these significant episodes of explosive dynamics in house prices in Australia in Figure 1 below. Multiple episodes of bubble-like house-price dynamics are also experienced in Canada, Ireland, Japan, Sweden and the UK. By contrast, Italy, Spain and Switzerland have each experienced two episodes of housing market exuberance, while the US has experienced only a single but very large episode of explosive growth in real house prices during the sample period. 

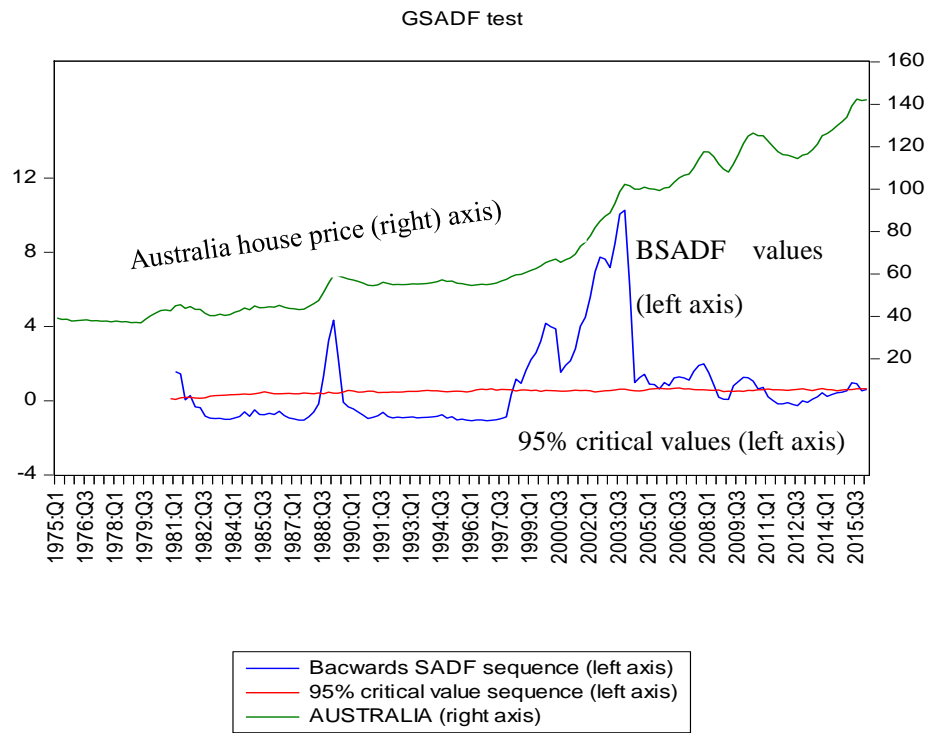

Figure 1. GSADF test for Australia

Second, Table 1 also reveals that most of the countries under investigation have experienced explosive growth in real house prices just prior to the great recession of 2008-2009. A close examination of the time-pattern of explosive dynamics suggests that investor exuberance in housing originated in the US, which experienced bubble-like explosive dynamics over the extended period 1997Q1-2007Q2. The US experience was then quickly propagated to other rich countries including Ireland (2002Q3-2007Q4), the UK (2006Q4-2008Q1), Canada (2002Q1-2008Q3), Australia (1998:Q2-1008Q2), Italy (2003Q1-2005Q2), Japan (2002Q2-2006Q4), Spain (2001Q1-2007Q4) and Sweden (2002Q1-2008Q3); Switzerland is the only country that did not experience exuberance prior to the great recession. This propagation pattern suggests that a common factor, such as the decline in long-term interest rates across countries, may have been responsible for the almost synchronous housing booms across so many countries. However, existing evidence from pooled models show that changes in, not just a single but several common factors, were responsible for the wide-spread housing market exuberance of the last decade (Pavlidis et al., 2015). In this section we show that, notwithstanding the close timing of exuberance, fundamental drivers of housing market exuberance differ widely across countries. To allow for this heterogeneity, we employ country-specific, rather than pooled models, with the aim to understand the role that country-specific fundamentals have played in generating bubble-like explosive growth in house prices in different countries.

Third, it is also noteworthy from table 1 that, in a majority of the countries under investigation, bubble-like explosive price dynamics ended prior to 2016Q1 - the last observation in our sample. Only three countries (Canada, Sweden and Switzerland) have continued to experienced explosive price dynamics even in 2016Q1. The practical significance of this finding is that the diagnostic tool we have used in this paper has the ability to detect abnormal price dynamics in the housing market right up to the latest period for which the relevant data are available. For example, it implies that a central bank that has access to housing price data right up to the current period (2017Q2) would have the ability to monitor housing market developments in real time.

Finally, it should be noted here that the dating chronology reported in table 1 is quite robust to changes in the number of lags ( $\mathrm{k}=1$ through 4$)$ in equation (1) but it is somewhat sensitive to a change in the indicator variable, in particular, when series $y_{t}$ in equation (1) refers to rent-to-price ratio, instead of the real house price series used in this paper. Furthermore, the dating chronology of explosive growth in real house prices reported in Table 1 has a special significance for our analysis that follows in the remainder of the paper. This is because we use this information as input into building country-specific multivariate probit models of the fundamental driver of houses prices in each country. The resulting models are estimated and used for analyzing the relative (quantitative) ability of the fundamentals versus the ability of the dynamics of the bubble process itself, in explaining/predicting the likelihood of future development of bubble-like explosive price dynamics in housing in each country. We take up these two issues in section 4 below.

\section{Predicting the Likelihood of Future Exuberance in Housing Markets}

In this section we employ country-specific probit models to determine whether bubble-like (explosive) growth in 
house prices reported in section 3 above are the result excessive speculative or unobserved changes in the fundamentals. The theoretical discussion presented in section 2 indicated that when explosive growth is driven by speculative exuberance it should leave a predictable pattern of autoregressive dynamics in house prices and when such growth is driven by changes in the fundamentals, it should typically produce a systematic pattern of cross-correlations. We therefore employ two variants of country-specific probit models: a static version to help us estimate the predictive ability of the fundamentals at different (1 to 6 quarters ahead) forecast horizons and a dynamic version to help us assess the additional predictive ability of the dynamics of the bubble process caused by speculative exuberance at the same forecast horizons.

\subsection{Specification of Country-Specific Probit Models}

The general functional form of our country-specific probit model may be described by the following equation:

$$
\operatorname{Pr}\left(B B L_{i, t}=1\right)=\Phi\left(x_{i, t} \beta_{i}\right)
$$

where $\Phi($.$) is the standard normal cumulative distribution function and \mathrm{x}_{\mathrm{i}, \mathrm{t}}$ is a vector of fundamental explanatory variables for country $\mathrm{i}=1,2, \ldots, 10$, and $\mathrm{BBL}_{\mathrm{i}, \mathrm{t}}$ is the binary $(0,1)$ bubble-indicator (dependent) variable that takes the value 1 if there is evidence of exuberance in the housing market in country $i$ and 0 otherwise. In the implementation of the model, we pay careful attention to three potential sources of misspecification that may potentially bias the model's predictive ability. These are (1) errors in the construction of the binary dependent variable $\mathrm{BBL}_{\mathrm{i}, \mathrm{t}}(2)$ errors in the choice of explanatory variables $\mathrm{x}_{\mathrm{i}, \mathrm{t}}$ and (3) errors in the specification of bubble dynamics. In the rest of this section, we describe each of these potential sources of misspecification along with our empirical responses designed to minimize each type of error.

\section{(1) Construction of Binary Dependent Variable BBL}

Inaccuracy in the construction of the binary dependent variable of the probit model is a potential source of specification bias. To minimize this source of bias, we construct the binary dependent variable BBL of the probit model by relying on the most accurate bubble-dating methodology available to date - the dating chronology of the GSADF test. More specifically, for each country in Table 1 above, we construct a binary $(0,1)$ bubble indicator variable $\mathrm{BBL}_{\mathrm{t}}$ such that,

$$
B B L_{t}=\left\{\begin{array}{l}
1 \quad \text { if there isevidence of } \exp \text { losive growth at timet, based on the GSADF test } \\
0 \quad \text { if there isno exp losive growth at timet, based on the GSADF test }
\end{array}\right.
$$

\section{(2) Choice of Fundamental Explanatory Variables, $\mathbf{x}_{t}$}

A wrong choice of the explanatory variables $\mathrm{x}_{\mathrm{i}, \mathrm{t}}$ for country i may also result in specification error. This source of error may easily occur because of a lack of consensus among researchers about a unique set of fundamental variables that drive housing bubbles (Mayer, 2011). To guard against this source of misspecification, we adopt a two-step empirical strategy. In step 1 , we assemble as a large set of 12 theoretically-motivated explanatory variables from competing housing-bubble theories, as potential drivers of housing market exuberance. These include several forward-looking financial variables namely, changes in short-term interest rate (DSTIR), changes in long-term interest rate (DLTR), the spread between the long and short term interest rates (SPRD), and growth rate of stock prices (GSTOK). While the short-term interest rate captures changes in monetary policy, the long term interest rate provides a financial measure of the opportunity cost of investing in housing; both these variables are expected to have a negative impact on house prices. The interest rate spread proxies for the slope of the yield curve and signals market expectations of future short term interest rates, it is expected to have a positive sign (Estrella \& Mishkin, 1998). Share price represents the profitability of an alternative class of assets to housing and is expected to have a negative sign.

We also incorporate the real GDP growth rate (GRGDP) and the growth rate of real GDP per capita (GRYPC) as potential drivers of housing booms. In theory, these demand-side variables are expected to have positive effects on house price growth. We also include in the initial set, the national unemployment rate (UN), in order to capture a possible cyclical effect on house price growth.

Our initial set of explanatory variables includes several measures of domestic private sector credit and monetary growth variables, including the growth in total mortgage loan (GMORT), growth in total private loan (GTHH), current account growth (CA), narrow money supply growth (GM1) and broad money growth (GM2). An expansion of domestic private credit growth can trigger a housing boom, and capital inflows from abroad can fuel a rapid expansion in domestic credit. Hence, all three variables GMORT, GTHH and CA are expected to have negative signs. Finally, theory suggests that growth of both narrow and broad money supply should have positive effects on housing prices.

Given the initial set of potential explanatory variables selected in step 1; in step 2 we determine the subset of the 
initial set that is empirically relevant to each country. To do this, we start by estimating a general probit model for each country that includes all twelve variables. The parameters of the model are estimated using the maximum likelihood estimator and the goodness-of-fit of the model is evaluated based on McFadden's $\mathrm{R}^{2}$ statistic. This statistic is estimated as $\mathrm{R}^{2}=[1-\log (\beta)] / \log (\beta)$, where $\log (\beta)$ is the restricted log likelihood. It is an analog to the $\mathrm{R}^{2}$ reported in linear regression models. It has the property that it always lies between zero and one.

Then we recursively reduce the model by deleting the statistically insignificant variables (variables with the highest $p$ values) until all remaining variables are statistically significant for each country. Estimation results for the country-specific probit models derived by this general-to-specific modelling procedure are reported in Table 2 below.

Table 2. Country-specific general-to-specific probit models: 1974Q1-2013Q4

\begin{tabular}{|c|c|c|c|c|c|c|c|c|c|}
\hline Country & $\mathrm{CA}$ & DLTR & GRYPC & GM2 & GMORT & GSTOK & UN & SPRD & McFadden's $\mathrm{R}^{2}$ \\
\hline Australia & $-0.03 * * *$ & & $2.11 * * *$ & & & & $-0.28 * * *$ & $-0.59 * *$ & 0.29 \\
\hline Canada & $-0.04 * * *$ & & & $0.38^{* * * *}$ & & & $-0.25^{* *}$ & & 0.53 \\
\hline Italy & $-0.01 * *$ & $-1.61 * *$ & & & $0.29 * * *$ & & & $0.61 * * *$ & 0.23 \\
\hline Japan & & & $1.61 * * *$ & & & & & $-0.63 * * *$ & 0.26 \\
\hline Norway & & & & & & & $-0.71 * * *$ & $0.70 * * *$ & 0.19 \\
\hline Spain & & -0.50 & & & & $-0.06^{*}$ & & $0.13 *$ & 0.08 \\
\hline Sweden & & & $1.11 * * *$ & & & & & & 0.11 \\
\hline Switz. & & & & $0.43 * *$ & & & & & 0.11 \\
\hline UK & $-0.05 * * *$ & & $0.74 * * *$ & & & $-0.10 * * *$ & $-0.29 * * *$ & & 0.39 \\
\hline USA & $0.00 * * *$ & & & & & & & & 0.41 \\
\hline
\end{tabular}

Note. $*, * *$ and $* * *$ denote statistical significance at the 10,5 and 1 percent levels respectively. Each equation includes a constant term. Each country equation reported above is derived by following general-to-specific modelling methodology: the general model for each country included 12 fundamental explanatory variables and the specific model reported in the table was derived by recursively eliminating the statistically insignificant (variables with the highest $\mathrm{p}$ values). The reported models show the diversity of the fundamental variables that have a statistically significant contemporaneous correlation with explosive growth in real house prices across countries.

Two interesting findings emerge from the results in Table 2. First, in spite of the timing proximity of investor exuberance found in the univariate test results reported in Table 1; Table 2 reveals that housing markets across countries are highly heterogeneous. This is evident from the fact that the statistically significant drivers of exuberance in housing differ greatly across countries. In fact, table 2 results provide little support to the role of declining long-term interest rates in the synchronization of domestic housing markets across countries. Instead, current account changes (which are highly significant for six of the ten countries) play a much bigger role, lending support to the view that international capital flows may contribute to the propagation of housing market exuberance across countries. This finding is further reinforced by the results for the US in table 2, which show that the explosive growth in real house prices experienced in the country during the period 1997Q1-2007Q2 were largely driven by two factors namely, domestic mortgage credit growth (GMORT), bolstered by capital inflows from abroad (CA).

Second, Table 2 also reveals that the statistically significant fundamental variables, as a group, have only a limited ability to explain contemporaneous explosive growth in real house prices in any of the countries in our sample. This is evident from the generally low values of McFadden's $\mathrm{R}^{2}$ statistic reported in the last column of table 2. In fact, the average $\mathrm{R}^{2}$ value for all countries is only 0.24 , with a minimum value of .07 (for Japan) and a maximum of 0.53 (for Canada). These rather low values of the goodness-of-fit statistic clearly leave a lot of room for speculative and other non-fundamental drivers of house prices to play an important role across countries. We pursue this issue further, below, by examining the ability of the fundamentals to predict future bubble formation in housing based on country-specific static and dynamic probit models.

\section{(3) Specification of Bubble dynamics}

The discussion of the modern bubble theories in section 2 suggested that episodes of explosive growth in house prices can arise either from changes in the fundamentals or from speculative exuberance of investors or a combination of the two. That discussion also showed that that speculative bubbles are likely to be characterized by strong momentum i.e., explosive growth in the last period is likely to followed similar growth in the current period. Ignoring such dynamics of the bubble process may result in misspecification and, therefore, bias the predictive ability of the model. We therefore employ two separate variants of country-specific probit models 
reported in Table 2: a static and a dynamic variant. The country-specific static model is formulated by using lagged values of the country-specific fundamentals from Table 2 for lags $\mathrm{k}=1,2 \ldots 6$ quarters. The dynamic model is derived by augmenting the static model with the lagged dependent variable, BBL (-1), as an additional explanatory variable. Given these formulations, the additional predictive ability of the dynamic model over the static counterpart should reveal how big a role autoregressive forces generated by expectations-driven speculative exuberance of homebuyers play for predicting future bubble formation in a country.

We report the estimation results for the country-specific static models in Table 3 below. It should be noted here that even though we have estimated both static (and dynamic) models for each of $\mathrm{k}=1$ through $\mathrm{k}=6$ quarter forecast horizons, we only report the results for horizons $\mathrm{k}=1, \mathrm{k}=3$ and $\mathrm{k}=6$, in order to save space.

A comparison of Table 3 results to those in Table 2 reveals that the static probit model has a somewhat superior predictive ability than the contemporaneous probit model in table 2 . This is evident from the fact that at all three forecast horizons $(\mathrm{k}=1, \mathrm{k}=3$ and $\mathrm{k}=6$ ), all country specific explanatory variables (except Spain) retain their strong statistical significance at the $1 \%$ level and, at the same time, the overall predictive performance of the model improves at each horizon. For example, at the one-quarter ahead forecast horizon $\mathrm{k}=1$, the average value of McFadden's $\mathrm{R}^{2}$ statistic for all countries is 0.26 compared to the corresponding average of 0.24 in table 2 . The predictive ability of the static model remains consistently stable even at the higher forecast horizons, with an average $\mathrm{R}^{2}$ of 0.27 at $\mathrm{k}=3$ and $\mathrm{R}^{2}$ of 0.25 at horizon $\mathrm{k}=6$. It is important to note, however, that despite the static model's somewhat superior relative predictive performance, its absolute performance remains rather low, with an average $\mathrm{R}^{2}$ value of 0.26 across all countries and all forecast horizons.

Table 3. Estimation results for the country-specific static probit models

\begin{tabular}{|c|c|c|c|c|c|c|c|c|c|c|}
\hline \multirow[t]{2}{*}{ Country } & \multirow[t]{2}{*}{ Lag } & \multicolumn{9}{|c|}{ Variable } \\
\hline & & $\mathrm{CA}$ & DLTR & GRYPC & GM2 & GMORT & GSTOK & $\mathrm{UN}$ & SPRD & $\mathrm{R}^{2}$ \\
\hline \multirow[t]{3}{*}{ Australia } & $\mathrm{K}=1$ & $-0.03 * * *$ & & $2.18 * * *$ & & & & $-0.35^{* * *}$ & $-0.80^{* *}$ & 0.35 \\
\hline & $\mathrm{K}=3$ & $-0.03 * * *$ & & $1.65 * * *$ & & & & $-0.42 * * *$ & $-1.38 * * *$ & 0.42 \\
\hline & $\mathrm{K}=6$ & $-0.03 * * *$ & & -0.08 & & & & $-0.23 * * *$ & $-0.86 * * *$ & 0.38 \\
\hline \multirow[t]{3}{*}{ Canada } & $\mathrm{K}=1$ & $-0.03 * * *$ & & & $0.36^{* * *}$ & & & $-0.37 * * *$ & & 0.46 \\
\hline & $\mathrm{K}=3$ & $-0.02 * * *$ & & & 0.13 & & & $-0.23 * *$ & & 0.28 \\
\hline & $K=6$ & $-0.01^{*}$ & & & -0.10 & & & -0.03 & & 0.17 \\
\hline \multirow[t]{3}{*}{ Italy } & $\mathrm{K}=1$ & $-0.01 * *$ & $-1.90^{* *}$ & & & $0.29 * * *$ & & & $0.57 * * *$ & 0.21 \\
\hline & $\mathrm{K}=3$ & $-0.01 * * *$ & $-1.45^{* *}$ & & & $0.22 * * *$ & & & $0.39 * * *$ & 0.17 \\
\hline & $K=6$ & $-0.02 * * *$ & $-0.66^{*}$ & & & $0.07 * *$ & & & 0.03 & 0.13 \\
\hline \multirow[t]{3}{*}{ Japan } & $\mathrm{K}=1$ & & & $1.51 * * *$ & & & & & $-0.69 * * *$ & 0.24 \\
\hline & $\mathrm{K}=3$ & & & $1.37 * * *$ & & & & & $-0.78 * * *$ & 0.23 \\
\hline & $K=6$ & & & $0.52 * *$ & & & & & $-0.63 * * *$ & 0.09 \\
\hline \multirow[t]{3}{*}{ Norway } & $\mathrm{K}=1$ & & & & & & & $-0.69 * * *$ & $0.66^{* * *}$ & 0.18 \\
\hline & $\mathrm{K}=3$ & & & & & & & $-0.54 * * *$ & $0.47 * * *$ & 0.12 \\
\hline & $\mathrm{K}=6$ & & & & & & & $-0.31 * * *$ & $0.23 * *$ & 0.04 \\
\hline \multirow[t]{3}{*}{ Spain } & $\mathrm{K}=1$ & & -0.39 & & & & -0.04 & & $0.14^{*}$ & 0.07 \\
\hline & $\mathrm{K}=3$ & & -0.41 & & & & -0.02 & & $0.22 * *$ & 0.12 \\
\hline & $K=6$ & & $-1.04 * *$ & & & & 0.01 & & $0.57 * *$ & 0.35 \\
\hline \multirow[t]{3}{*}{ Sweden } & $\mathrm{K}=1$ & & & $1.07 * * *$ & & & & & & 0.10 \\
\hline & $\mathrm{K}=3$ & & & $0.75^{* * *}$ & & & & & & 0.06 \\
\hline & $\mathrm{K}=6$ & & & 0.33 & & & & & & 0.02 \\
\hline \multirow[t]{3}{*}{ Switz. } & $\mathrm{K}=1$ & & & & $0.34 *$ & & & & & 0.08 \\
\hline & $\mathrm{K}=3$ & & & & 0.24 & & & & & 0.04 \\
\hline & $\mathrm{K}=6$ & & & & 0.09 & & & & & 0.02 \\
\hline \multirow[t]{3}{*}{ UK } & $\mathrm{K}=1$ & $-0.06^{* * *}$ & & $0.67 * *$ & & & $-0.09^{* *}$ & $-0.36^{* * *}$ & & 0.44 \\
\hline & $\mathrm{K}=3$ & $-0.09 * * *$ & & $0.73 * *$ & & & $-0.11 * * *$ & $-0.68^{* * *}$ & & 0.57 \\
\hline & $K=6$ & $-0.05^{* * * *}$ & & $-0.76^{* *}$ & & & $-0.08 * *$ & $-0.71 * * *$ & & 0.50 \\
\hline \multirow[t]{3}{*}{ USA } & $\mathrm{K}=1$ & $0.00 * * *$ & & & & & & & & 0.46 \\
\hline & $\mathrm{K}=3$ & $-0.01 * * *$ & & & & & & & & 0.56 \\
\hline & $\mathrm{K}=6$ & $-0.01 * * *$ & & & & & & & & 0.75 \\
\hline
\end{tabular}

Note. ${ }^{*}, * *$ and $* * *$ denote statistical significance at the 10, 5 and 1 percent levels respectively. Each equation includes a constant term. Each country equation reported above is derived by following general-to-specific modelling methodology; by recursively eliminating the statistically insignificant (variables with the highest $\mathrm{p}$ values). DataSource: Jordà-Schularick-Taylor Macrohistory Database http://www.macrohistory.net/data/ 
We now turn to the estimation results from the dynamic variant of the probit model reported in Table 4. Even a cursory comparison of these results to those in Table 3 immediately reveals the crucial importance of dynamics for our ability to predict future bubble formation in housing markets.

Table 4. Estimation results for the country-specific dynamic models

\begin{tabular}{|c|c|c|c|c|c|c|c|c|c|c|c|}
\hline \multirow[t]{2}{*}{ Country } & \multirow[t]{2}{*}{ Lag } & \multicolumn{10}{|c|}{ Variable } \\
\hline & & $\mathrm{CA}$ & DLTR & GRYPC & GM2 & GTHH & GSTOK & $\mathrm{UN}$ & SPRD & BBL(-1) & $\mathrm{R}^{2}$ \\
\hline \multirow[t]{3}{*}{ Australia } & $\mathrm{K}=1$ & 0.00 & & 2.65 & & & & -2.53 & $-1.96 * *$ & $8.23 * *$ & 0.92 \\
\hline & $\mathrm{K}=3$ & $-0.27 * * *$ & & $-13.35^{* * * *}$ & & & & -0.30 & $-2.85^{* *}$ & $22.21 * * *$ & 0.94 \\
\hline & $\mathrm{K}=6$ & $-0.07 *$ & & $-3.16^{* * *}$ & & & & 0.31 & 0.23 & $6.10 * * *$ & 0.88 \\
\hline \multirow[t]{3}{*}{ Canada } & $\mathrm{K}=1$ & $-0.03 *$ & & & 0.17 & & & $-0.38 * *$ & & & 0.78 \\
\hline & $K=3$ & 0.00 & & & -0.21 & & & 0.10 & & & 0.74 \\
\hline & $K=6$ & 0.00 & & & -0.28 & & & 0.27 & & & 0.77 \\
\hline \multirow[t]{3}{*}{ Italy } & $\mathrm{K}=1$ & $-0.01 * * *$ & $-2.09 * *$ & & & $0.22 * *$ & & & $0.31 * *$ & $2.94 * * *$ & 0.66 \\
\hline & $K=3$ & $-0.01 * *$ & 0.10 & & & 0.07 & & & 0.06 & $3.04 * * *$ & 0.65 \\
\hline & $K=6$ & $-0.02 *$ & -0.63 & & & -0.17 & & & -0.34 & $3.56^{* * *}$ & 0.68 \\
\hline \multirow[t]{3}{*}{ Japan } & $\mathrm{K}=1$ & & & 0.53 & & & & & $-0.32 *$ & $3.05^{* * *}$ & 0.72 \\
\hline & $\mathrm{K}=3$ & & & 0.65 & & & & & $-0.36^{* *}$ & $3.03^{* * * *}$ & 0.72 \\
\hline & $\mathrm{K}=6$ & & & -0.61 & & & & & -0.06 & $3.54 * * *$ & 0.71 \\
\hline \multirow[t]{3}{*}{ Norway } & $\mathrm{K}=1$ & & & & & & & -0.23 & 0.19 & $2.98 * * *$ & 0.69 \\
\hline & $\mathrm{K}=3$ & & & & & & & 0.02 & -0.12 & $3.21 * * *$ & 0.68 \\
\hline & $K=6$ & & & & & & & 0.05 & -0.03 & $3.14 * * *$ & 0.67 \\
\hline \multirow[t]{3}{*}{ Spain } & $\mathrm{K}=1$ & & $0.97 *$ & & & & $0.11 * * *$ & & $0.34 * *$ & $4.47 * * *$ & 0.79 \\
\hline & $K=3$ & & -0.57 & & & & $0.09^{*}$ & & $0.49 * *$ & $5.01 * * *$ & 0.83 \\
\hline & $\mathrm{K}=6$ & & -1.23 & & & & 0.06 & & $0.55 * * *$ & $4.02 * * *$ & 0.84 \\
\hline \multirow[t]{3}{*}{ Sweden } & $\mathrm{K}=1$ & & & 0.30 & & & & & & $3.65^{* * *}$ & 0.79 \\
\hline & $K=3$ & & & -0.04 & & & & & & $3.74 * * *$ & 0.79 \\
\hline & $\mathrm{K}=6$ & & & -0.56 & & & & & & $4.06^{* * *}$ & 0.81 \\
\hline \multirow[t]{3}{*}{ Switz. } & $\mathrm{K}=1$ & & & & $-0.57 * *$ & & & & & $4.72 * * *$ & 0.83 \\
\hline & $\mathrm{K}=3$ & & & & -0.20 & & & & & $4.19 * * *$ & 0.81 \\
\hline & $\mathrm{K}=6$ & & & & -0.27 & & & & & $3.88 * * *$ & 0.80 \\
\hline \multirow[t]{3}{*}{ UK } & $\mathrm{K}=1$ & $-0.05^{* * *}$ & & 0.16 & & & -0.04 & $-0.32 * *$ & & 3.23 & 0.81 \\
\hline & $\mathrm{K}=3$ & $-0.03^{* *}$ & & -0.31 & & & $-0.15^{*}$ & $-0.33^{*}$ & & 3.30 & 0.82 \\
\hline & $\mathrm{K}=6$ & -0.02 & & $-1.15^{* * *}$ & & & -0.04 & $-0.34 * *$ & & 3.08 & 0.79 \\
\hline
\end{tabular}

Note. $*, * *$ and $* * *$ denote statistical significance at the 10,5 and 1 percent levels respectively. Each equation includes a constant term. Each country equation reported above is derived by following general-to-specific modelling methodology; by recursively eliminating the statistically insignificant (variables with the highest $\mathrm{p}$ values). The dynamic model for the US could not be estimated due to covariance singularity. Data Source: Jordà-Schularick-Taylor Macrohistory Database http://www.macrohistory.net/data/

The dominance of dynamics over the fundamental variables shows up in several metrics. First, the lagged depended variable BBL (-1) is statistically highly significant (at the $1 \%$ significance level) at all forecast horizons ( $\mathrm{k}=1, \mathrm{k}=3$ and $\mathrm{k}=6)$ and across all countries. Second, the existence of BBL(1) in the model drives down the predictive ability of the fundamentals across all countries, but particularly in Canada, Japan, Norway, Sweden, and Switzerland, compared to static model in Table 3. Finally and most notably, the presence of BBL $(-1)$ in the model dramatically improves the overall goodness-of-fit of the model, as captured by McFadden's $\mathrm{R}^{2}$ statistics, across all countries. For example, compared to the Table 3 average $\mathrm{R}^{2}$ value for all countries of 0.25 at $\mathrm{k}=1,0.27$ at $\mathrm{k}=3$, and 0.25 at $\mathrm{k}=6$, the corresponding $\mathrm{R}^{2}$ values at the same horizons in Table 4 are $0.77,0.77$ and 0.77 respectively. Thus, the results reported in table 4 provide strong support to the view that the dynamics of the bubble process (i.e., explosive growth in the current period is likely to be associated with similarly strong growth in the next period as well) is a key characteristic of housing bubbles; ignoring this characteristic may seriously impair our ability to anticipate the likelihood of bubble-like explosive growth in house prices in future periods.

\section{Conclusions and Discussion}

This paper addresses an empirical puzzle in the housing bubble literature: models of market fundamentals perform poorly in explaining investor exuberance in housing even though, individually, many fundamentals have a strong ability to predict explosive growth in real house prices. We explore two plausible sources for the poor 
performance: missing fundamentals and missing bubble dynamics. To shed light on the relative importance of these sources, we conduct a detailed two-step investigation of the housing markets in ten rich countries using models, methodologies and datasets that are similar to those employed in the existing literature. In step 1 we identify and also date stamp exuberance in housing (explosive growth in real house prices), using the powerful GSADF test. The evidence from the GSADF test shows that all ten countries have experienced at least one major episode of housing market exuberance over the period 1975Q1 - 2016Q1; a few countries have experienced three episodes, and three of the countries (Canada, Sweden and Switzerland) have continued to experience bubble-like growth in house prices even in the most recent observation in the sample period.

In step 2, we use estimated bubble chronologies from step 1 to construct multivariate country-specific probit models of market fundamentals using the general-to-specific modelling strategy. The evidence from our probit model analysis leads to several notable conclusions. First, results from the static probit model shows that, despite the timing-synchronicity of exuberance implied by the GSADF test results, housing markets are highly heterogeneous across countries. This is evident from the fact that the fundamental variables that have a significant ability to explain/predict exuberance in the housing market vary widely across countries. Interestingly, our findings also show that the country-specific fundamentals, as a group, only have a limited ability to predict future bubble formation in any country, as measured by the average McFadden $\mathrm{R}^{2}$ value across all countries and all forecast horizons.

Perhaps the most important finding of the paper is that augmenting the static model with the lagged dependent variable markedly improves the predictive performance of the model. The additional variable which captures the momentum of the housing bubble process is highly significant at all forecast horizons and across all countries and its presence in the model drives down the significance of the fundamental variables across all countries. Most importantly, the dynamic version of the model has a notably superior ability to anticipate the likelihood future development of bubble-like exponential growth in house prices. This is evident in the fact that the dynamic version of the model has a much larger average $\mathrm{R}^{2}$ value for all countries and all forecast horizons. The robustness and consistency of this finding suggests that a proper accounting of dynamics of the bubble process is crucial to our understanding and monitoring of housing market developments.

Finally, it should be noted that the findings of this paper are subject to an important caveat. During the sample period, each individual country has experienced only one or at most two or three large episodes of housing market exuberance. The lack of sufficiently long bubble chronologies for individual countries has forced us to focus on only in-sample predictive abilities, which may not always translate to out-of-sample predictive ability. One way to relax this constraint is to study the predictive abilities of pooled models. But pooling comes with a cost because it imposes housing-market homogeneity across countries. Ideally, what is needed is a longer sample period that covers multiple episodes of investor exuberance in housing in each country.

\section{References}

Blanchard, O. (1979). Speculative bubbles, crashes and rational expectations. Economic Letters, 3, 387-389. https://doi.org/10.1016/0165-1765(79)90017-X

Estrella, A., \& Mishkin, F. S. (1998). Predicting U.S. recessions: Financial variables as leading indicators. The Review of Economics and Statistics, 80(1), 45-61. https://doi.org/10.1162/003465398557320

Evans, G. W. (1991). Pitfalls in testing for explosive bubbles in asset prices. American Economic Review, 81, 922-930. http://www.jstor.org/stable/2006651

Himmelberg, C., Mayer, C., \& Sinai, T. (2005). Assessing high house prices: Bubbles, fundamentals, and $\begin{array}{lllll}\text { misperceptions. Journal of } & \text { Economic }\end{array}$ https://doi.org/10.1257/089533005775196769

Igan, D., \& Loungani, P. (2012). Global Housing Cycles. International Monetary Fund Working Paper, WP/12/217, 1-55. https://doi.org/10.5089/9781475505672.001

International Monetary Fund. (2016). The Global Housing Watch. IMF, April. Retrieved from http://www.imf.org/external/research/housing/

Kindleberger, C. (1978). Manias, panics and crashes: A history of financial crises. New York. Basic Books. https://doi.org/10.1007/978-1-349-04338-5

Mayer, C. (2011). Housing Bubbles: A Survey. Annual Review of Economics, 3, 559-577. https://doi.org/10.1146/annurev.economics.012809.103822

Pavlidis, E., Yusupova, A., Paya, I., Peel, D., Martinez-Garcia, E., Mack, A., \& Grossman, A. (2016). Episodes of 
Exuberance in Housing Markets in Search of a Smoking Gun. The Journal of Real Estate Finance and Economics, 53(4), 419-449. https://doi.org/10.1007/s11146-015-9531-2

Peterson, B., \& Zheng, Y. (2011-2012). Medium-term fluctuations in Canadian house prices. Bank of Canada Review, winter, 30-42. https://core.ac.uk/download/pdf/6552600.pdf

Phillips, P. C. B., \& Yu, J. (2011). Dating the timeline of financial bubbles during the subprime crisis. Quantitative Economics, 2(3), 455-49. https://doi.org/10.3982/QE82

Phillips, P. C. B., Shi, S., \& Yu, J. (2013). Testing for bubbles 1: Historical episodes of exuberance and collapse in the S\&P 500. SMU Economics and Statistics Working Paper Series, Paper No. 04-2013. https://doi.org/10.2139/ssrn.2327609

Shiller, R. (2000). Measuring bubble expectations and investor confidence. Journal of Psychology and Financial Markets, 1, 49-60. https://doi.org/10.1207/S15327760JPFM0101_05

Shiller, R. (2003). From Efficient Markets Theory to Behavioral Finance. Journal of Economic Perspective, 17(1), 83-104. https://doi.org/10.1257/089533003321164967

Shiller, R. (2005). Irrational Exuberance (2nd ed.). Princeton University Press.

Summers, L. H. (1986). Does the stock market reflect fundamental values? The Journal of Finance, 41(3), 591-601. https://doi.org/10.1111/j.1540-6261.1986.tb04519.x

Tsatsaronis, K., \& Zhou, H. (2004). What drives house price dynamics: Cross- country evidence. BIS Quarterly Review, Bank of International Settlement, March, 65-78. Retrieved from https://www.bis.org/publ/qtrpdf/r_qt0403f.pdf

Turner, A. (2013). The Consequences of Money-Manager Capitalism. Speech given to the Institute for New Economic Thinking, October 25. Retrieved from https://www.youtube.com/watch?v=6QYBTE5hQyI

\section{Copyrights}

Copyright for this article is retained by the author(s), with first publication rights granted to the journal.

This is an open-access article distributed under the terms and conditions of the Creative Commons Attribution license (http://creativecommons.org/licenses/by/4.0/). 